\title{
Histone deacetylases meet microRNA-associated MMP-9 expression regulation in glucocorticoid-sensitive and -resistant cell lines
}

\author{
MARWA HENTATI-KALLEL ${ }^{1}$, SÉBASTIEN LE JAN ${ }^{1}$, PHILIPPE BERNARD ${ }^{1,2}$, \\ FRANK ANTONICELLI $^{1,2}$ and AURÉLIE TRUSSARDI-RÉGNIER ${ }^{1}$ \\ ${ }^{1}$ EA7319 Derm-I-C, Health Center, ${ }^{2}$ Department of Dermatology, University Hospital Center, \\ University of Reims-Champagne-Ardenne, 51096 Reims, France
}

Received October 11, 2016; Accepted November 21, 2016

DOI: $10.3892 /$ ijo.2016.3830

\begin{abstract}
Glucocorticoids are largely used in the treatment of inflammatory pathologies and/or hematological malignancies and regulate the expression of a variety of genes involved in inflammation or metastasis such as matrix metalloproteinases (MMP). Long-term exposure to glucocorticoids can result in failure of responsiveness, which is often associated with an unwanted gene expression. Epigenetic mechanisms are involved in gene expression modulated after development of glucocorticoid resistance but how these mechanisms take place must be further studied. The effects of HDAC inhibitors (HDACi) in a context of glucocorticoid resistance are still not well understood and need to be further investigated. We hypothesized that acquired glucocorticoid resistance associated to HDACi could disturbs epigenetic landscape, especially miR expression, leading to a modulation of MMP-9 gene expression and/or protein secretion, described as largely involved in bone remodeling and tumor invasion in multiple myeloma. To this aim, we used sensitive RPMI- 8226 cell line and its dexamethasone- and methylprednisolone-resistant derivatives. The resistant cell lines displayed an 'open chromatin' and an MMP-9 overexpression comparatively to the sensitive cell line. HDACi treatment with MS-275 increased even more MMP-9 overexpression not only at an mRNA level but also at the protein level. We showed that MMP-9 expression regulation was not directly linked with HAT/ HDAC balance alterations but rather with the deregulation of MMP-9-targeting miRs. Then, we first demonstrated that miR-149 downregulation was directly involved in the MMP-9 overexpression following a chronic glucocorticoid exposure
\end{abstract}

Correspondence to: Dr Aurélie Trussardi-Régnier, EA7319 Derm-I-C, Health Center, University of Reims Champagne-Ardenne, 1 Avenue du Maréchal Juin, 51096 Reims, France

E-mail: aurelie.trussardi@univ-reims.fr

Key words: glucocorticoid resistance, MMP-9, microRNA, HDAC inhibitors, MS-275 and that MS-275 could amplify this overexpression by inhibition of miR-149 expression and miR-520c overexpression. Taken together, these results indicate that the use of HDACi in a context of acquired glucocorticoid resistance could modify the epigenetic landscape, highlighting the importance of taking the glucocorticoid response status into consideration in treatment with HDACi.

\section{Introduction}

Synthetic glucocorticoids have been widely used not only as treatment for inflammatory and autoimmune diseases but also for some hematological malignancies such as multiple myeloma, leukemia and lymphomas (1-3). However, longterm chronic exposure to glucocorticoids can lead to the development of glucocorticoid resistance and results in failure of responsiveness, which is often associated with an unwanted gene expression (4-6). Through the glucocorticoid receptor (GR) pathway, glucocorticoids regulate the expression of a variety of genes involved in inflammation or metastasis such as matrix metalloproteinases (MMP), which are largely known as extracellular matrix remodeling proteins. MMP-9/gelatinase B is a member of the MMP protein family (7-9). In inflammatory diseases, the MMP-9 overexpression is downregulated by steroid treatment but often greater increased after glucocorticoid resistance development. The mechanisms associated to this MMP-9 expression modulation are partially understood (6,10-13). Notably several epigenetic mechanisms have been correlated with the glucocorticoid resistance phenomenon (14-16). One of the well-described glucocorticoid resistance mechanisms has been associated with a change in histone acetylation status due to reduced histone deacetylase 2 (HDAC2) activity, subsequently and dramatically increasing the expression of inflammatory gene such as TNF- $\alpha$, IL-8 and MMP-9 in inflammatory lung diseases (17-22). Besides its implication in the inflammatory processes, the relationship between glucocorticoid resistance, HDACs regulation and gene expression modulation can also be of importance for tumor cell progression (23). In multiple myeloma, the MMP-9 plays a critical role in tumor invasion (24-26). However, the impact of new therapeutics 
associating glucocorticoids and HDACs inhibitors (HDACi) on the MMP-9 expression is not elucidated (27-29).

Transcriptome regulation is also under the control of microRNAs (miRs), which interact with mRNA as a post-transcriptional regulator of gene expression. Glucocorticoid treatment has been shown to up- or downregulate miR expression resulting in gene expression alterations. In turn, modulation of miR expression by glucocorticoid treatment may lead to glucocorticoid resistance (14,30-32). However, how the HDACs meet miR-associated glucocorticoid resistance still need further investigation.

The aim of this study was to evaluate the impact of a glucocorticoid long-term exposure associated or not to HDACi treatment on the epigenetic control of MMP-9 expression and secretion in multiple myeloma. Our findings could deepen the understanding of the epigenetic response associated with glucocorticoid resistance to later on provide different therapeutic strategies.

\section{Materials and methods}

Chemicals. Dexamethasone, methylprednisolone and MS-275 (entinostat) were purchased from Sigma-Aldrich (Saint-Quentin Fallavier, France). The solutions of dexamethasone and methylprednisolone were prepared at $10 \mathrm{mM}$ with absolute ethanol and stored at $-20^{\circ} \mathrm{C}$. MS -275 was dissolved in dimethylsulfoxide (DMSO) to obtain an initial concentration of $0.1 \mathrm{mM}$.

Cell culture. The RPMI-8226 human multiple myeloma cell (8226wt) and its glucocorticoid-resistant variants $8226 \mathrm{~d}$ and $8226 \mathrm{~m}$ selected upon long-term treatment with dexamethasone and methylprednisolone respectively, were kindly provided by Pr J. Dufer (Reims, France) and cultured as previously described $(33,34)$. All experiments were performed with cells in exponential growth phase. Cell viability was evaluated using trypan blue staining, all experiments were carried out with at least $95 \%$ of cell viability.

RNA extraction and reverse-transcription real-time polymerase chain reaction $\left(R T^{2}-P C R\right)$. After treatment in a serum free medium, $2 \times 10^{6}$ cells were washed twice in ice-cold Dulbecco's phosphate-buffered saline (D-PBS) and total RNA extraction was performed according to Chomczyński method with TRIzol ${ }^{\mathrm{TM}}$ reagent (Life Technologies, Villebon sur Yvette, France) (35). One microgram of total RNA was reverse-transcribed using Moloneymurine leukemia virus reverse-transcriptase (M-MLV; Invitrogen, Cergy Pontoise, France) and random primers in a $20 \mu 1$ final volume. MMP-9 and $\beta 2$ microglobulin $(\beta 2 m)$ transcripts were analyzed by semi-quantitative $\mathrm{RT}^{2}$-PCR using the following gene-specific oligonucleotide primers (Invitrogen): MMP-9 forward, 5'-TGACAGCGACAAGAAGTGG-3' and reverse, 5'-GGCGAGGACCATAGAGGTG-3'; $\beta 2 \mathrm{~m}$ forward, 5'-ACCCC CACTGAAAAAGATGA-3' and reverse, 5'-ATCTTCAAACC TCCATGATG-3'. Real-time-PCR was performed on the LightCycler ${ }^{\circledR}$ machine (Roche, Meylan, France) with platinum $S^{S Y B R}{ }^{\circledR}$-Green qPCR supermix-UDG (Life Technologies). Relative quantification was performed using the $\beta 2 \mathrm{~m}$ housekeeping gene as internal control. Gene expression level was calculated as $2^{-\Delta \mathrm{Ct}}$ where $\Delta \mathrm{Ct}=$ target $\mathrm{Ct}-\beta 2 \mathrm{~m} \mathrm{Ct}$ [cycle threshold $(\mathrm{Ct})]$.
Zymography. Quantity of proMMP-9 was determined on conditioned media by the zymography technique. Briefly, samples were electrophoresed on a 9\% SDS-polyacrylamide-gel impregnated with $0.1 \%$ of gelatin as substrate under nonreducing conditions (9). The gels were subsequently fixed and stained with $0.25 \%$ Coomassie brilliant blue R-250 to visualize the proteolytic activity bands. Quantification was performed using ImageJ software (36).

Western blot analysis. Total protein extraction from $4 \times 10^{6}$ cells was realized on ice with RIPA buffer. To prevent proteolysis and maintain acetylation status, protease inhibitor cocktail (Roche) and $0.01 \mathrm{M}$ butyric acid (Sigma-Aldrich) were added to the buffer. After centrifugation $\left(11,500 \mathrm{rpm}, 4^{\circ} \mathrm{C}, 10 \mathrm{~min}\right)$, supernatants were harvested and the protein concentration was quantified. Isolation of nuclear and cytoplasmic proteins was performed on $10 \times 10^{6}$ cells as previously described (37). Western blot analysis was performed using $20 \mu \mathrm{g}$ of proteins separated by a $10 \%$ gel or $15 \%$ gel for histone using SDS-PAGE, and probed after transfer onto nitrocellulose membrane with primary antibodies diluted in $1 \%$ nonfat milk in TBS-T [mouse anti- $\alpha$-tubulin-human $(1 / 500$, DM1A, monoclonal antibody; Calbiochem, Meudon, France); rabbit anti-HDAC2-human (1/2,000, PA1-861, polyclonal antibody; Thermo Scientific, Courtaboeuf Cedex, France); rabbit anti-acetylated histone $\mathrm{H}_{4}$-human $(1 / 1,000,06-866$, polyclonal antibody; Millipore, Lyon, France); goat anti-lamin B-human (1/500, C-20, polyclonal antibody; Santa Cruz Biotechnology, Inc., Heidelberg, Germany)]. Immune complex was revealed using a specific peroxydase-conjugated secondary antibody (donkey anti-rabbit IgG horseradish peroxidase (HRP) conjugate, 1/10,000, NA934, polyclonal antibody; Fisher Scientific, GE Healthcare, Saclay, France; goat anti-mouse IgG HRP conjugate, 1/5,000, 12-294, polyclonal antibody; Upstate Biotechnology, Saint-Quentin-en-Yvelines, France; mouse antigoat/sheep IgG HRP conjugate, 1/20,000, A9452, monoclonal antibody; Sigma-Aldrich) and the enhanced chemiluminescent (ECL) detection kit (GE Healthcare). Chemiluminescence signals were quantified by densitometry using NIH ImageJ analysis software. Target signals were normalized to specific housekeeping signals (lamin B or $\alpha$-tubulin).

Histone deacetylase assays: HDAC assays. Nuclear proteins $(30 \mu \mathrm{g})$ were analyzed for HDAC activity using the colorimetric HDAC assay kit (catalog no. 56210; Active Motif, La Hulpe, Belgium). Briefly, samples were incubated in presence of their substrate in 96-well plates for $2 \mathrm{~h}$ at $37^{\circ} \mathrm{C}$. Then, HDAC activity was assayed by measuring optical density at $405 \mathrm{~nm}$ in a microtiter plate following manufacturer's instructions.

Histone acetyltransferase assays: HAT assays. Nuclear HAT activity (from $50 \mu \mathrm{g}$ of nuclear proteins) was measured using the colorimetric HAT assay kit according to the manufacturer's instructions (catalog no. K332-100; Biovision, CliniSciences, Nanterre, France). Briefly, samples were incubated in the presence of the substrate in 96-well plates for $1 \mathrm{~h}$ at $37^{\circ} \mathrm{C}$ and HAT activity was assayed by measuring optical density at $440 \mathrm{~nm}$ in a microtiter plate.

Epigenetic $R T^{2}-P C R$ array. After genomic DNA elimination, total RNA $(1 \mu \mathrm{g})$ was reverse-transcribed using the 
$\mathrm{RT}^{2}$ first strand kit (SABiosciences, Qiagen, Courtaboeuf, France) according to the manufacturer's instructions. The cDNA template was amplified using the ready-to-used $\mathrm{RT}^{2}$ SYBR-Green Master Mix qPCR and the human epigenetic chromatin modification enzyme $\mathrm{RT}^{2}$ profiler ${ }^{\mathrm{TM}}$ PCR array (PAHS-085A) (both from SABiosciences, Qiagen) which allow the detection of DNA methyltransferases, histone acetyltransferases, histone methyltransferases, SET domain proteins (histone methyltransfesase activity), histone phosphorylation, histone ubiquitination, DNA/histone demethylases, histone deacetylase gene expression levels. cDNA amplification was carried out on the Stratagene Mx3005P qPCR system (Agilent Technologies, France). Ct of targeted genes were normalized by the mean of five housekeeping $\mathrm{Ct}$, and expressions were expressed as $2^{-\Delta \mathrm{Ct}}$. Fold-regulation of $8226 \mathrm{~d}$ and $8226 \mathrm{~m}$ cell gene expressions were determined relatively to $8226 \mathrm{wt}$ gene expressions.

Chromatin immunoprecipitation (ChIP). Magna ChIP ${ }^{\mathrm{TM}}$ A/G kit (Millipore) was used to perform ChIP experiments. Analysis were realized according to the manufacturer's protocol as previously described (9). Briefly, nuclei suspension from $10 \times 10^{6}$ cells was sonicated on ice and 10-fold diluted in IP dilution buffer containing 1X protease inhibitor cocktail II (Roche). Before immunoprecipitation, $1 \%$ of the diluted chromatin solution was kept as input. The diluted chromatin solution was incubated overnight at $4^{\circ} \mathrm{C}$ with $5 \mu \mathrm{g}$ of the anti-RNApol II or $10 \mu \mathrm{g}$ antiacetylated histone $\mathrm{H}_{4}$ antibodies (mouse anti-RNApol II-human, monoclonal antibody: 05-623, rabbit anti-acetylated histone $\mathrm{H}_{4}$-human, polyclonal antibody: 06-866; Millipore) and with $20 \mu \mathrm{l}$ of resuspended protein $\mathrm{A} / \mathrm{G}$ magnetic beads. After washing, the cross-linking between DNA and proteins was reversed and DNA was purified. Four microliters of diluted DNA (1/50) samples were analyzed by RT2 - PCR (LightCycler ${ }^{\circledR}$; Roche) with platinum SYBR $^{\circledR}$-Green qPCR supermix-UDG in presence of $0.5 \mu \mathrm{M}$ of each primers: TSS (-86 to +33 from transcription site, NG_011468.1): forward, 5'-TGACCCCTGA GTCAGCACTT-3' and reverse, 5'-CTGCCAGAGGCTCAT GGTGA-3' or promoter (-660 to -487 from transcription site, NG_011468.1): forward, 5'-TGTCCCCTTTACTGCCCTGA-3' and reverse, 5'-ACTCCAGGCTCTGTCCTCTT-3' using a Tm at $58^{\circ} \mathrm{C}$. Enrichment level was calculated as $2^{-\Delta \mathrm{Ct}}$ where $\Delta \mathrm{CT}=$ target $\mathrm{Ct}$-input $\mathrm{Ct}$.

MicroRNA $R T^{2}-P C R$. RNA $(1 \mu \mathrm{g})$ was reverse-transcribed using miScript II RT kit (Qiagen) as described in manufacturer's protocol. Seven miRs were used: 5 miRs described to be involved in the direct or indirect pathway of MMP-9 expression (miR-149, miR-149*, miR-212, miR-491 and miR-520c) and 2 miRs (miR-3123 and miR-3145) found in silico data with the miRDB data bank (http://mirdb.org). Expression level of each miR was quantified by real-time PCR using target specific miScript primers [forward primers, miR-149 (MS00003570), miR-149* (MS00037702), miR-212 (MS00003815), miR-491 (MS00031899), miR-520c (MS00007413), miR-3123 (MS00042077) and the miScript SYBR-Green PCR kit (all from Qiagen)], which also contains the miScript universal primer (reverse primer) and QuantiTect SYBR-Green PCR Master Mix. The human RNU6B (forward primer, MS00033740; Qiagen) miScript primer was used as internal normalized reference. PCR was performed on $2 \mu 1$ of cDNA (100-fold diluted) as follow: $95^{\circ} \mathrm{C}$ for $15 \mathrm{~min}, 50 \mathrm{ampli}$ fication cycles of $95^{\circ} \mathrm{C}$ for $15 \mathrm{sec}, 55^{\circ} \mathrm{C}$ for $30 \mathrm{sec}$ and $70^{\circ} \mathrm{C}$ for $30 \mathrm{sec}$ on the LightCycler ${ }^{\circledR}$ II. Level of miR expressions was obtained by using the $2^{-\Delta \mathrm{Ct}}$ methods where $\Delta \mathrm{Ct}=$ target Ct-RNU6B Ct.

miR mimic and anti-miR transfection. The $8226 \mathrm{wt}, 8226 \mathrm{~d}$ and $8226 \mathrm{~m}$ cell lines were transfected using HiPerFect transfection reagent (Qiagen) according to manufacturer's protocol with $1 \mu \mathrm{g}$ of AllStars Hs cell death control siRNA (positive control; Qiagen) to establish cell transfection efficiency (estimated at $95 \%, 48 \mathrm{~h}$ post-transfection with trypan blue exclusion assay). Experiments were conducted with $1 \mu \mathrm{g}$ of AllStars Hs cell death control siRNA, AllStars negative control siRNA (mock, negative control), anti-hsa-miR-149 (miR-149 inhibitor, MIN0000450), syn-hsa-miR-149 (miR-149 mimic, MSY0000450), anti-hsa-miR-520c (miR520c inhibitor, MIN0002846) or syn-hsa-miR-520c (miR-520c mimic, MSY0002846) (all from Qiagen). Briefly, a mix containing $1 \mu \mathrm{g}$ of siRNA or miR and $9 \mu \mathrm{l}$ of HiPerFect transfection reagent was added to cell culture without fetal calf serum (FCS) for $8 \mathrm{~h}$, and then medium was replaced by complete medium (RPMI-1640 glutamax medium supplemented with $10 \%$ of FCS, and $1 \%$ of antibiotics). Eighteen hours before gathering for zymography analysis as described above, cells were deprived of FCS and treated or not with $10 \mu \mathrm{M}$ of MS-275.

\section{Results}

MMP-9 expression is upregulated in glucocorticoid-resistant cells. Wild-type RPMI-8226 cells (8226wt), dexamethasone resistant cells (8226d) and methylprednisolone resistant cells $(8226 \mathrm{~m})$ were cultured for $18 \mathrm{~h}$ in a corticoid- and serum-free medium to investigate long-term steroid-induced resistance effects on MMP-9 expression by $\mathrm{RT}^{2}$-PCR and zymography analysis. $M M P-9$ mRNA level was upregulated in $8226 \mathrm{~d}$ and in $8226 \mathrm{~m}$ resistant cells (7- and 18 -fold, respectively) compared to wild-type 8226 cells (Fig. 1A). Accordingly, MMP-9 secretion was significantly increased in resistant cells with respect to control cells (1.5- and 2.5 -fold in $8226 \mathrm{~d}$ and $8226 \mathrm{~m}$ cells, respectively) (Fig. 1B and C).

Histone acetylation is upregulated in glucocorticoid-resistant cells. We then investigated whether among the several molecular mechanisms proposed to explain reduced steroid responsiveness and then MMP-9 upregulation, the acetylated histone level was modulated in our cellular model. Compared to 8226wt cells, western blot analysis revealed that histone $\mathrm{H}_{4}$ acetylation level was significantly increased by 1.5 - and 1.8 -fold in 8226d and 8226m resistant cells, respectively (Fig. 2A and B). However, the increase of $\mathrm{H}_{4}$ acetylation was not associated with a modification of HDAC2 protein expression in the three cell lines tested (Fig. 2C and D). To further investigate whether the alteration of the HAT/HDAC balance could be involved in the $\mathrm{H}_{4}$ acetylation upregulation, we measured both global HAT and HDAC activities in the three cell lines using specific colorimetric assays. Global HDAC activities were similar in both sensitive and resistant cells (Fig. 3A), whereas global HAT activities were significantly upregulated in $8226 \mathrm{~d}$ cells (1.9-fold) 

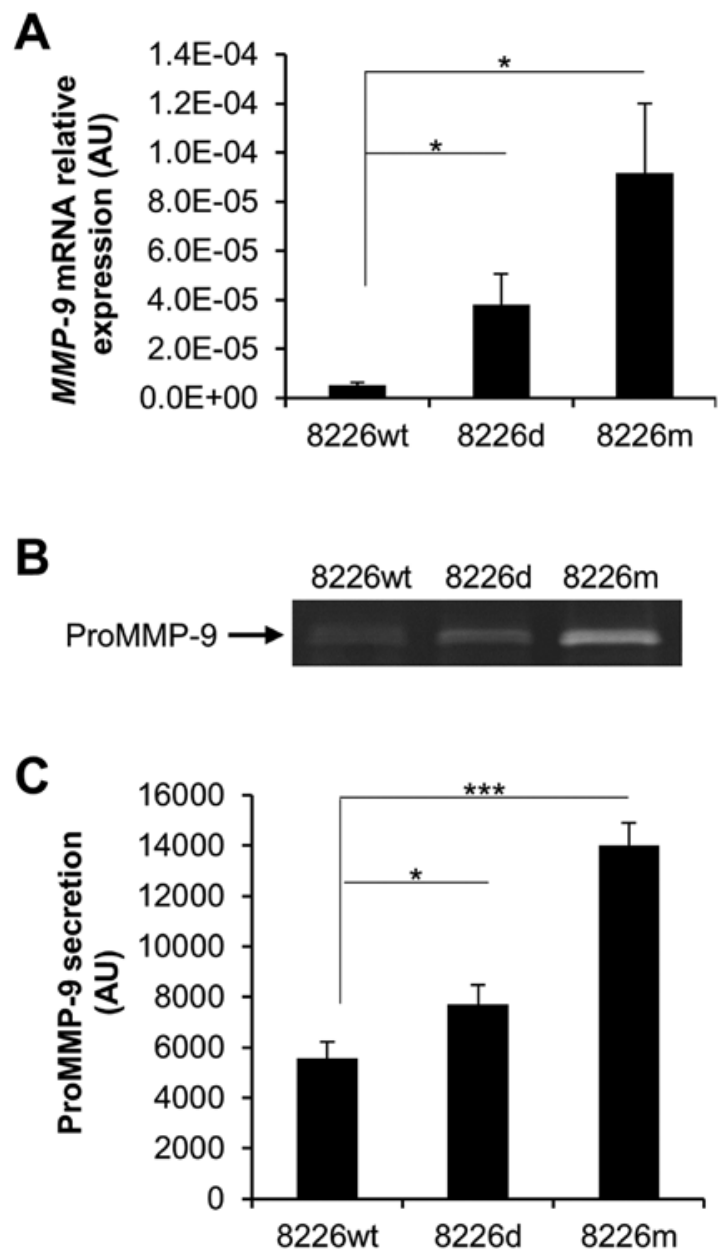

Figure 1. Upregulation of MMP-9 expression in glucocorticoid-resistant cells: $8226 \mathrm{wt}, 8226 \mathrm{~d}$ and $8226 \mathrm{~m}$ cells were cultured without glucocorticoid and FCS for $18 \mathrm{~h}$. (A) MMP-9 mRNA levels were analyzed by RT²-PCR. $\beta 2$ microglobulin $(\beta 2 m)$ was used as internal control. Results were expressed as normalized MMP-9/ $\beta 2 m$ ratio. (B) ProMMP-9 secretion analysis were performed by zymography. Conditioned culture medium was harvested after $18 \mathrm{~h}, 10$-fold concentrated and loaded on zymography gel. (C) Quantification of zymography gels was achieved with ImageJ software. All experiments were performed at least in triplicate. Results were expressed as mean \pm SEM. Significant $\mathrm{p}$-values (Student's t-test) are indicated as ${ }^{*} \mathrm{p}<0.05,{ }^{* *} \mathrm{p}<0.01$ and $* * * * 0.001$.

and $8226 \mathrm{~m}$ cells (2.5-fold) (Fig. 3B) compared with $8226 \mathrm{wt}$ cells. To further investigate the epigenetic influence of steroid resistance on MMP-9 expression in our cellular model, we analyzed by $\mathrm{RT}^{2}$-PCR 84 key genes encoding enzymes known to regulate chromatin accessibility. Expression of seven genes varied in $8226 \mathrm{~d}$ and $8226 \mathrm{~m}$ resistant cells compared to $8226 \mathrm{wt}$ cells. Apart for HDAC9 in $8226 \mathrm{~d}$, no variation was observed in expression of other histone deacetylase genes. Within the histone acetyltransferase family group, NCOA1 expression was increased in $8226 \mathrm{~d}$ and in $8226 \mathrm{~m}$ ( $>2$-fold). Besides enzymes involved in the HAT/HDAC balance, we also found that the DNMT3B DNA methyltransferase expression was upregulated in $8226 \mathrm{~m}$ (>2-fold), while the SMYD3 histone methyltransferase expression was downregulated in both $8226 \mathrm{~d}$ and $8226 \mathrm{~m}$ (>2-fold). Also, the KDM5B histone lysine demethylase was downregulated in 8226d and 8226m ( $>4$-fold). Finally, expression of NEK6 and PAK1, involved in histone phosphorylation was downregulated in both $8226 \mathrm{~d}$ and $8226 \mathrm{~m}$ (Fig. 3C).
HDAC inhibition enhancedMMP-9 secretion in glucocorticoidsensitive and -resistant 8226 cells. To further demonstrate the importance of histone acetylation in glucocorticoid resistanceassociated MMP-9 expression, we used different class of HDAC inhibitors. Treatment with the pan-inhibitor suberoylanilide hydroxamic acid (SAHA) for $18 \mathrm{~h}$ in corticoid- and serum-free medium significantly upregulated MMP-9 mRNA expression in the three cell lines by 250-, 68- and 16-fold in the 8226wt, $8226 \mathrm{~d}$ and $8226 \mathrm{~m}$ cells, respectively (Fig. 4A). Similarly, all class I HDAC inhibitors used such as MS-275, valproic acid (VPA), and apicidin also largely upregulated $M M P-9$ mRNA expression in these cell lines. The most important effect was obtained with MS-275, which increased approximately by 1700-, 200- and 90-fold the MMP-9 mRNA expression in the 8226wt, 8226d and 8226m cell lines, respectively (Fig. 4A). No significant variation of MMP-9 mRNA level was observed using the class II inhibitor MC1568 (Fig. 4A). Although basal $M M P-9$ mRNA level differed between the three cell lines analyzed, the MMP-9 mRNA levels reached after MS-275 treatment were similar in those cells (Fig. 4A). Zymography analysis showed that both the pan-inhibitor and class I HDAC inhibitors significantly upregulated MMP-9 secretion, whereas the class II inhibitor remained ineffective (Fig. 4B and C). Like for mRNA expression, MS-275 effects on MMP-9 secretion were more pronounced than other class I HDAC inhibitors. However, MS-275-cell stimulation led to a weaker increase of MMP-9 secretion in glucocorticoid resistance cells compared to $8226 w$ t cells, contrary to the MMP-9 secretion observed in untreated cells.

Increase in MMP-9 expression and secretion did not only rely on the gene transcription upregulation. To better understand MS-275 effects on MMP-9 expression regulation in glucocorticoid-resistant cells, we carried out ChIP experiments using primers encompassing the -86 to +33 region (transcription start site, TSS) and the upstream -660 to -487 region, which contain the main DNA response elements for the transcriptional regulation of the MMP-9 promoter (NG_011468.1, from transcription site). ChIP experiments were conducted with RNApol II antibody to analyze $M M P-9$ gene transcriptional activity, and with an antibody against acetylated $\mathrm{H}_{4}$ to investigate $M M P-9$ promoter accessibility to the transcriptional machinery. Immunoprecipitation with the acetylated $\mathrm{H}_{4}$ antibody revealed that the basal accessibility of the TSS region was significantly increased in the two resistant cell lines compared with the 8226wt cells (2.2- and 4.7-fold for 8226d and 8226m respectively, $\mathrm{p}<0.05)$, and was further significantly enhanced upon MS-275 treatment in the three cell lines (Fig. 5A, right panel). Concomitantly the basal accessibility of the promoter upstream region was only increased in the $8226 \mathrm{~m}$ cells with respect to $8226 w t$ cells, and increased in all cell lines upon MS-275 treatment $(\mathrm{p}<0.01)$, although such increase was observed after $12 \mathrm{~h}$ stimulation with MS-275 in the $8226 \mathrm{~m}$ cell line (data not shown). The use of the RNApol II antibody showed that both the TSS and upstream regions were similarly involved in the MMP-9 gene basal transcription in the three cell lines, and were not affected by MS-275 treatment (Fig. 5B).

miR-149 and miR-520c are inversely regulated in glucocorticoid-resistant cells after MS-275 treatment. As the MMP-9 

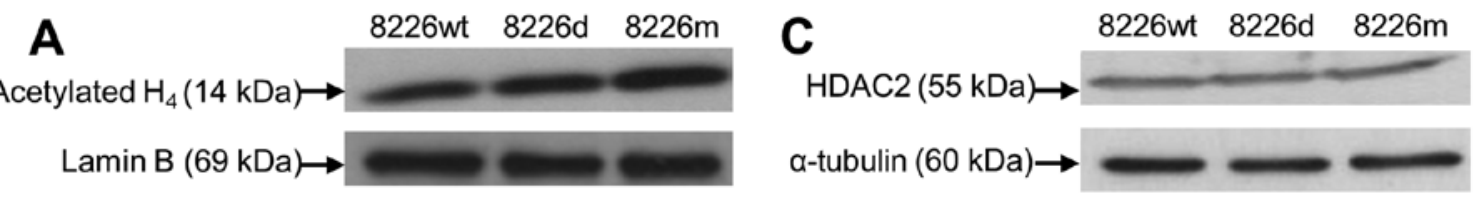

B

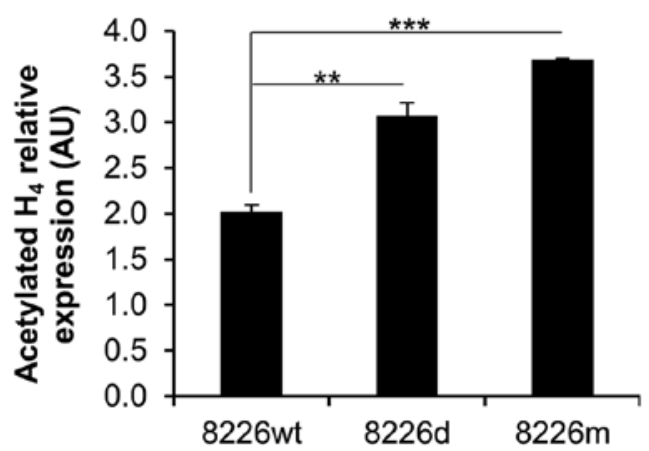

D

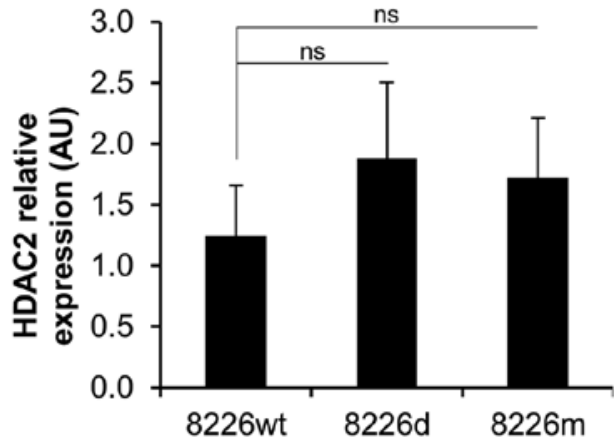

Figure 2. Upregulation of histone acetylation without HDAC2 expression modification in glucocorticoid-resistant cells: 8226wt, 8226d and 8226m cells were cultured without glucocorticoid and FCS for $18 \mathrm{~h}$. (A and C) Histone $\mathrm{H}_{4}$ acetylation and HDAC2 levels were analyzed by western blotting. (B and D) Quantification of bands of western blotting was achieved with ImageJ software. Results were expressed as the ratio of target band density normalized by lamin B (for acetylated histone $\mathrm{H}_{4}$ ) or $\alpha$-tubulin (for HDAC2) band density. All experiments were performed at least in triplicate. Results were expressed as mean \pm SEM. Significant $\mathrm{p}$-values (Student's t-test) are indicated as ${ }^{*} \mathrm{p}<0.05,{ }^{* *} \mathrm{p}<0.01$ and ${ }^{* * *} \mathrm{p}<0.001$.
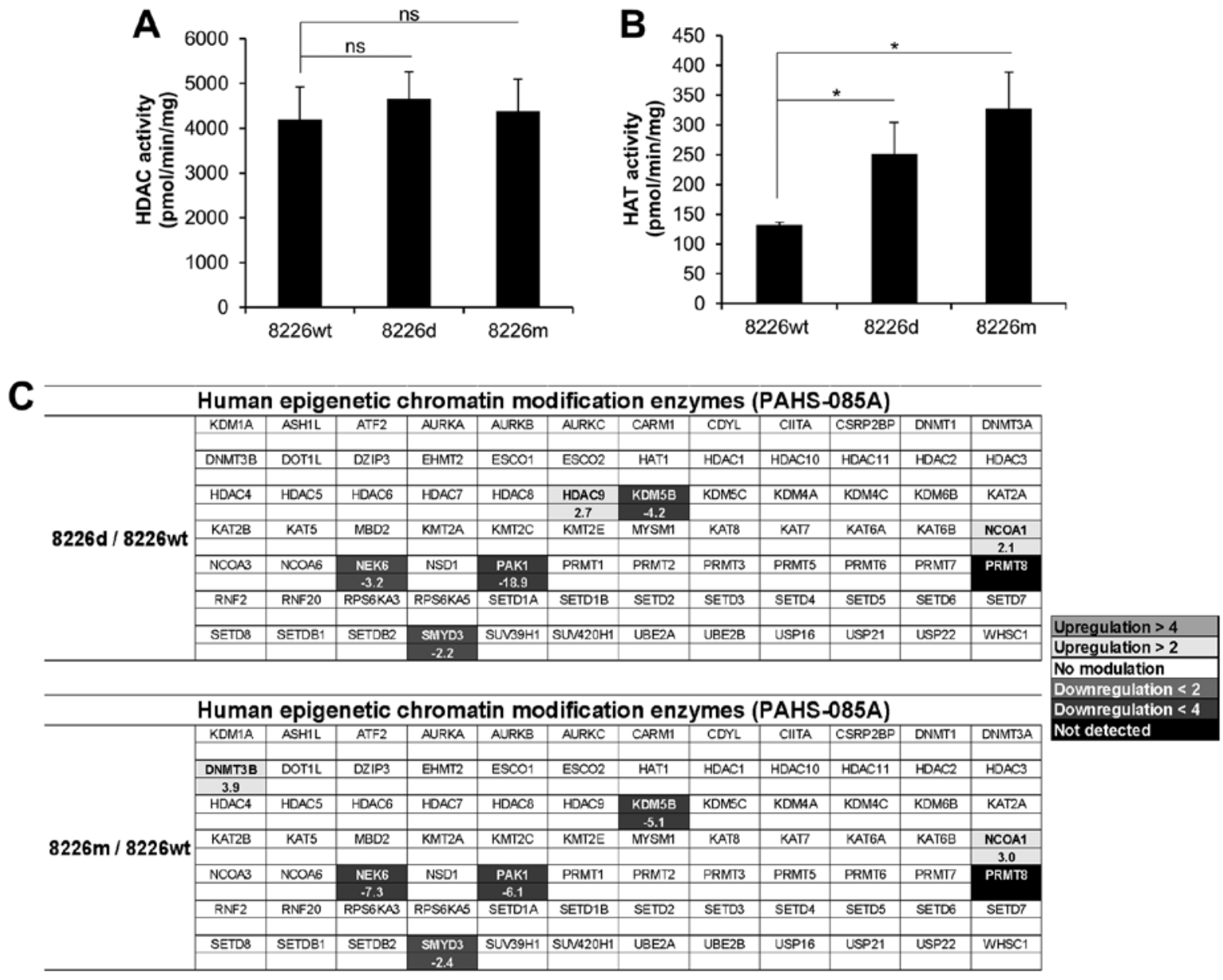

Figure 3. Alteration of the HAT/HDAC balance and epigenetic modulators in glucocorticoid-resistant cells: 8226wt, 8226d and 8226m cells were cultured without glucocorticoid and FCS for $18 \mathrm{~h}$. HAT and HDAC activities from nuclear extracts of each cell line were measured with colorimetric assay. (A) HDAC activity quantification at $405 \mathrm{~nm}$. (B) HAT activity quantification at $440 \mathrm{~nm}$. Results were expressed as mean \pm SEM. Significant p-values (Student's t-test) are indicated as ${ }^{*} \mathrm{p}<0.05,{ }^{* *} \mathrm{p}<0.01$ and ${ }^{* * *} \mathrm{p}<0.001$. (C) Epigenetic modulator alterations were analyzed by $\mathrm{RT}^{2}$-qPCR using 'the human epigenetic chromatin modification enzyme RT ${ }^{2}$ profiler ${ }^{\mathrm{TM}}$ PCR array' (PAHS-085A; SABiosciences; Qiagen, Courtaboeuf, France). Relative quantification of gene expression was established by comparing $\mathrm{Ct}$ values for each studied gene with the ones obtained from control genes (housekeeping genes) using the $\Delta \Delta \mathrm{Ct}$ method. All experiments were performed at least two times in duplicate. Gene expression modulations were considered of statistical significance when fold-change values were equal or greater than 2 -fold. 

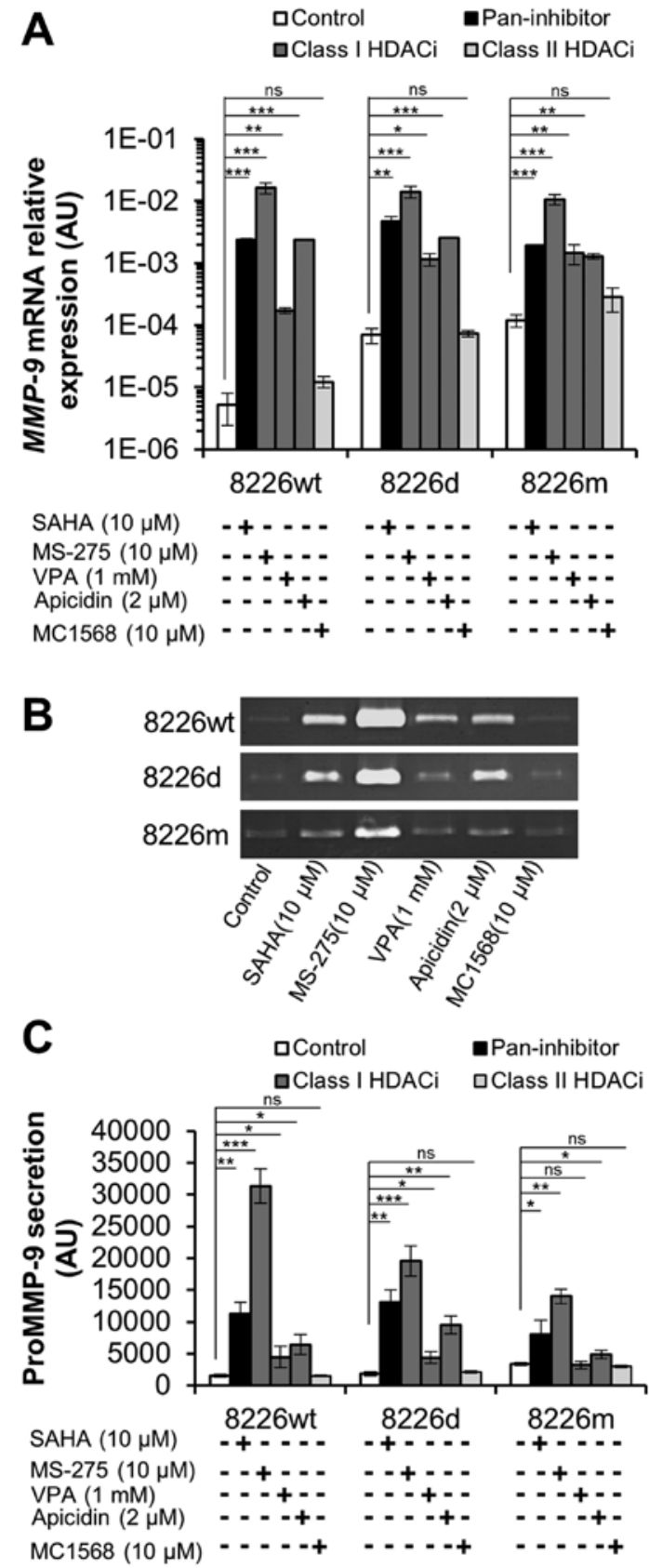

Figure 4. Differential upregulation of MMP-9 expression and secretion after HDACi treatment: $8226 \mathrm{wt}, 8226 \mathrm{~d}$ and $8226 \mathrm{~m}$ cells were treated with HDAC (pan inhibitor: SAHA $10 \mu \mathrm{M}$, class I HDAC inhibitor: MS-275 $10 \mu \mathrm{M}$, VPA $1 \mathrm{mM}$, apicidin $2 \mu \mathrm{M}$ or class II HDAC inhibitor: MC1568 $10 \mu \mathrm{M}$ ) for $18 \mathrm{~h}$ in culture medium without glucocorticoid and FCS. (A) MMP-9 mRNA levels were analyzed by $\mathrm{RT}^{2}$-PCR. $\beta 2$ microglobulin $(\beta 2 m)$ was used as internal control. Results were expressed of normalized $M M P-9 / \beta 2 m$ ratio. (B) ProMMP-9 secretion analysis were performed by zymography. Conditioned culture medium was harvested after $18 \mathrm{~h}, 10$-fold concentrated and loaded on zymography gel. (C) Quantification of zymography gels was achieved with ImageJ software. All experiments were performed at least in triplicate. Results were expressed as mean \pm SEM. Significant p-values (Student's t-test) are indicated as ${ }^{*} \mathrm{p}<0.05,{ }^{* *} \mathrm{p}<0.01$ and ${ }^{* * *} \mathrm{p}<0.001$.

promoter study could only partially explain the basal variation of MMP-9 expression, we focused our attention on the expression of several miRs that could be involved in the MMP-9 expression regulation. Although the miR-149 was expressed in the three cell lines, its basal expression was significantly downregulated in the glucocorticoid-resistant cells as compared with the 8226wt glucocorticoid-sensitive cell line, and completely abolished in the three cell lines after treatment with MS-275 (Fig. 6A). Conversely, the miR-520c was not expressed in the untreated cell lines, and was induced upon MS-275 stimulation (Fig. 6B). No expression variation was observed between the three cell lines neither before nor after MS-275 treatment for the miR-149*, miR-212, miR-491 and miR-3123 (Fig. 6C-F). Finally, the miR-3145 was not detected in our cell lines (data not shown).

To validate the potential implication of the miR-149 and miR-520c in the regulation of MMP-9 expression at the basal and MS-275 stimulated conditions respectively, we performed either gain- or loss-of-function experiments using pre-miR (miR mimic) or anti-miR (miR inhibitor) delivered by cell transfection. The reduction of the miR-149 expression level in 8226 wt cell transfected with the miR-149 inhibitor was associated with a basal upregulation of MMP-9 secretion (Fig. 7A). Inversely, miR-149 overexpression following $8226 \mathrm{~d}$ and $8226 \mathrm{~m}$ cell transfection with the miR-149 mimic decreased the basal upregulation of MMP-9 secretion observed in the resistant non-transfected cells (Fig. 7B and C). The investigation of the role of the miR-520c in the MS-275 associated modulation of MMP-9 secretion revealed a downregulation of the MMP-9 secretion in the three sensitive and resistant cell lines (8226wt, $8226 \mathrm{~d}$ and 8226m) transfected with the miR-520c inhibitor. No MMP-9 secretion modulation was observed in miR-520c mimic transfected cell lines (Fig. 7D-F).

\section{Discussion}

In this study, we evaluated the impact of a glucocorticoid long-term exposure on the epigenetic mechanisms and its consequences on MMP-9 expression and secretion. We showed that a long-term exposure to glucocorticoids disturbed the HAT/HDAC balance and the miR expression leading to MMP-9 overexpression. Moreover, we showed that the miR altered pattern associated to glucocorticoid-induced resistance interfered on later HDACi-mediated MMP-9 regulation.

Compared with glucocorticoid-sensitive cells, dexamethasone and methylprednisolone-resistant cell lines displayed an increased expression of MMP-9, both at the mRNA and protein level. MMP-9 enhanced expression correlated with an increase of $\mathrm{H}_{4}$ acetylation, which reflects a higher level of chromatin accessibility in these drug-resistant cells. Then, our results were in line with previous studies demonstrating that alterations of epigenetic mechanisms in glucocorticoid-resistant cells, were directly associated with increased expression of proinflammatory or metastasis genes $(18,20,38)$. However, in our glucocorticoid-resistant cells the hyperacetylation was not bound to a decreased HDAC expression and activity, and especially not to HDAC2, a class I histone deacetylase shown to switch off inflammatory genes upon steroids treatment in asthma and chronic obstructive pulmonary disease or lung cancer $(17,19,39)$. Instead, a more important HAT activity was observed in both resistant cell lines (8226d and 8226m), and notably the steroid receptor coactivator 1 (SRC1/NCOA1) expression. Considering the complexity of the histone code, NCOA1 overexpression could be associated with other epigenetic partners to increase accessibility to the chromatin and upregulate the $M M P-9$ transcription in resistant cells. For 

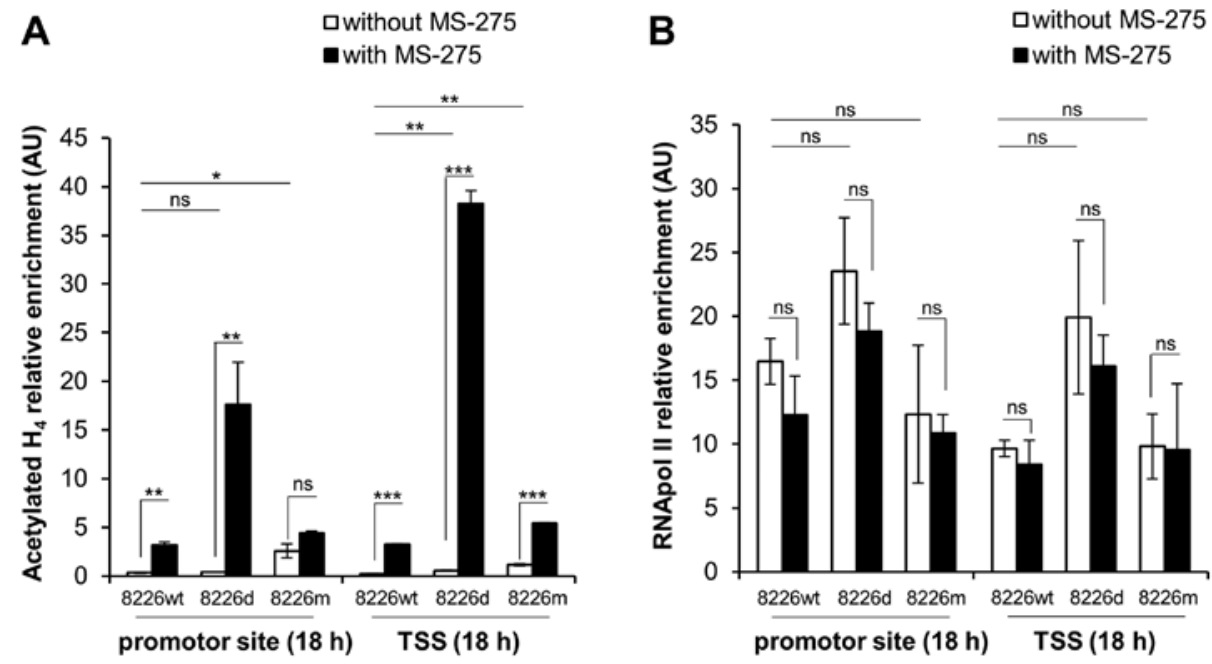

Figure 5. Acetylated $\mathrm{H}_{4}$ enrichment and RNApol II recruitment at the promoter site and TSS of MMP-9 gene: 8226wt, 8226d and 8226m cells were treated with class I HDAC inhibitor: MS-275 $(10 \mu \mathrm{M})$ for $18 \mathrm{~h}$ in culture medium without glucocorticoid and FCS. (A) Chromatin immunoprecipitation (ChIP) analysis on MMP-9 promoter site and TSS for the acetylated $\mathrm{H}_{4}$ relative enrichment. (B) ChIP analysis on MMP-9 promoter site and TSS for the RNApol II relative recruitment. Results were monitored by real-time PCR and were normalized with total input. Results were expressed by using the $2^{-\Delta C t}$ methods where $\Delta \mathrm{Ct}=\mathrm{Ct}_{\mathrm{IP}}-\mathrm{Ct}_{\mathrm{input}}$. Data are the mean $\pm \mathrm{SEM}$ of four independent experiments. Significant p-values (Student's t-test) are indicated as ${ }^{*} \mathrm{p}<0.05,{ }^{* *} \mathrm{p}<0.01$ and ${ }^{* * *} \mathrm{p}<0.001$.
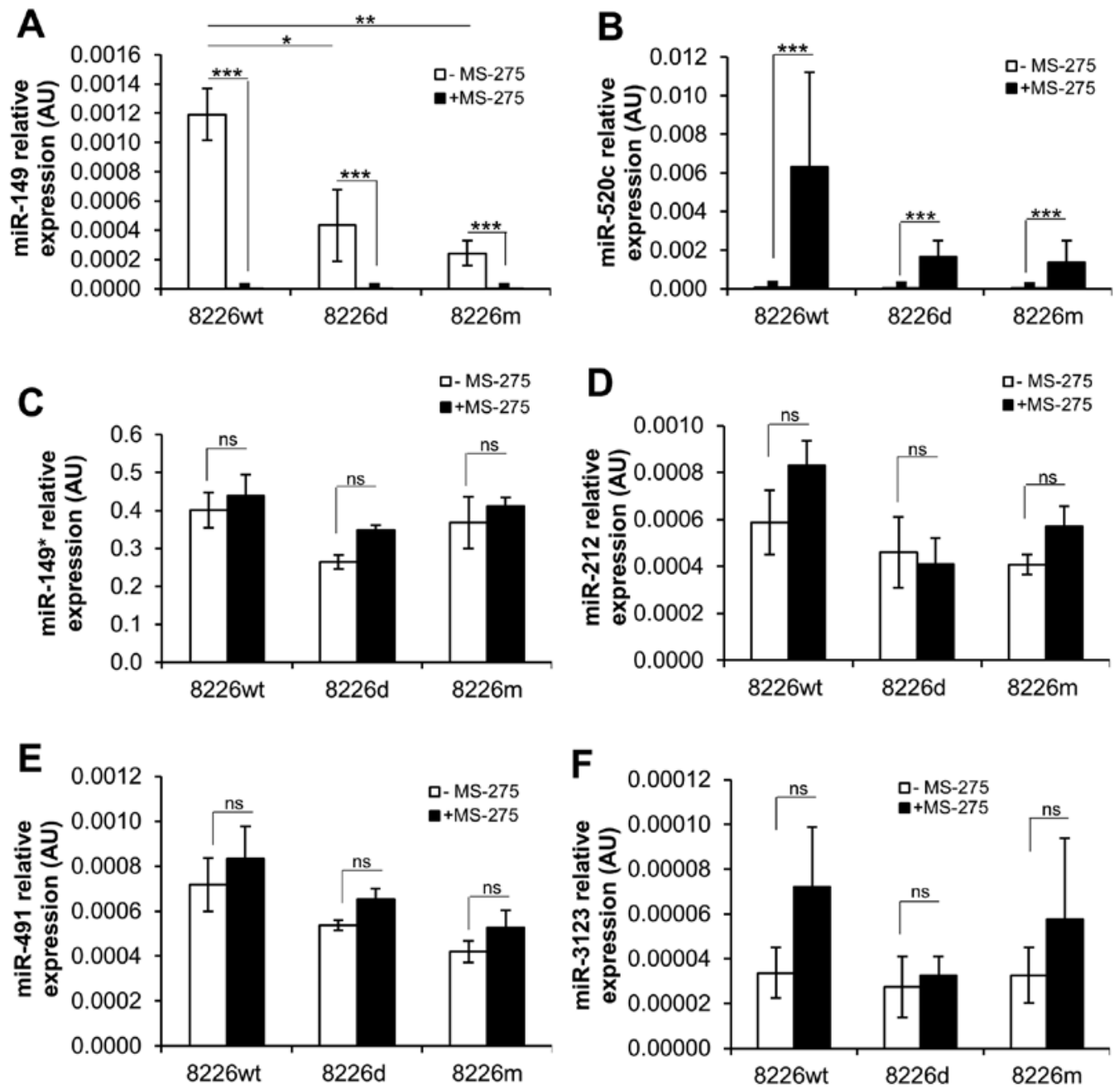

Figure 6. Up- and downregulation of MMP-9 expression involved miR in glucocorticoid-resistant cells treated or not with MS-275: 8226wt, 8226d and 8226m cells were treated or not with $10 \mu \mathrm{M}$ of MS-275 for $18 \mathrm{~h}$ in culture medium without glucocorticoid and FCS. RNA was extracted from the cells then miRs were amplified by RT ${ }^{2}$-PCR. [(A-F) Relative expression (arbitrary unit) of respectively miR-149, miR-520c, miR-149*, miR-212, miR-491 and miR-3123)]. Relative expression was established by comparing $\mathrm{Ct}$ for each studied miR with the ones obtained from RNU-6B using the $\Delta \mathrm{Ct}$ method. All experiments were performed at least in triplicate. Results were expressed as mean \pm SEM. Significant p-values (Student's t-test) are indicated as ${ }^{*} \mathrm{p}<0.05,{ }^{* * *} \mathrm{p}<0.01$ and ${ }^{* * * *} \mathrm{p}<0.001$. 

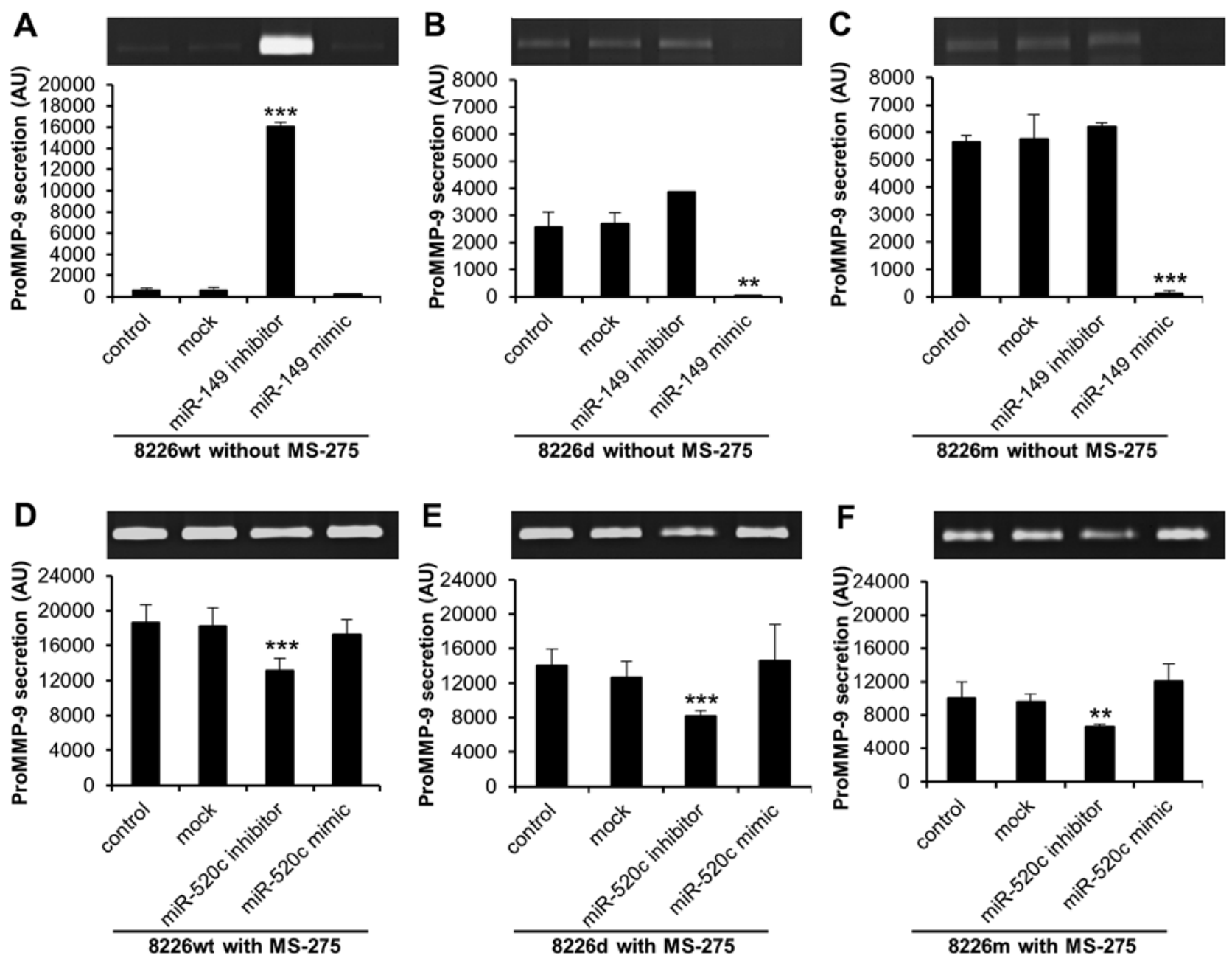

Figure 7. Up- and downregulation of MMP-9 secretion by miR-149 and miR-520c in glucocorticoid-resistant cells treated or no with MS-275: (A and D) 8226wt, (B and E) 8226d and (C and F) 8226m cell lines were transfected using the AllStars negative control siRNA (mock), anti-hsa-miR-149 (miR-149 inhibitor) and syn-hsa-miR-149 (miR-149 mimic) or anti-hsa-miR-520c (miR-520c inhibitor) and syn-hsa-miR-520c (miR-520c mimic). miR-149 regulation effects on proMMP-9 secretion were analyzed after $36 \mathrm{~h}$ and those of miR-520c after $64 \mathrm{~h}$. Eighteen hours before gathered for zymography analysis, cells were deprived of FCS and treated or not with $10 \mu \mathrm{M}$ of MS-275. All experiments were performed triplicate. Results are expressed as mean \pm SEM. Significant $\mathrm{p}$-values (Student's t-test) are indicated as ${ }^{*} \mathrm{p}<0.05,{ }^{* *} \mathrm{p}<0.01$ and $^{* * * *} \mathrm{p}<0.001$.

example, we also found a down-regulation of histone lysine demethylase (KDM5B, 4-fold), which likely resulted in an accumulation of lysine 4 of histone $\mathrm{H}_{3}\left(\mathrm{H}_{3} \mathrm{~K}_{4}\right)$ methylation (an active mark) and could lead to an increase of MMP-9 gene transcription. Then, HDAC1 and HDAC2 functions could be counterbalanced by compensatory epigenetic mechanisms interacting on repressive/active mark balance such as the $\mathrm{H}_{3} \mathrm{~K}_{4}$ methylation modulation as previously described (40). However, no transcriptional activity modulation was found between our cell lines neither at the $M M P-9$ promoter site nor at the TSS of $M M P-9$.

Taken together, these results suggested the involvement of a post-transcriptional mechanism such as microRNAs involved in the epigenetic regulation of MMP-9 expression. Indeed, in our model, we found that expression of the miR-149 was reduced in glucocorticoid-resistant cells with respect to sensitive cells and was inversely expressed to MMP-9 secretion. This was further consolidated by transfection of our cell lines with pre- or anti-miR-149 experiments, which showed a direct inversed link between the expressions of the miR-149 and MMP-9. Then, we highlighted here for the first time that glucocorticoid long-term exposure can induce drug resistance and perturb MMP-9 secretion via miR-149 expression modulation. Although the mechanisms by which miR control gene expression have been well demonstrated (41-43), the mechanisms involved in miR regulation remain complex. As above mentioned, glucocorticoid resistance modified the HAT/HDAC balance, leading to an enhanced histone acetylation level and to an 'open chromatin'. Although this increase of chromatin accessibility, we found decreased miR-149 expression, suggesting that the level of $M M P-9$ mRNA is rather related to an epigenetic modulation of $\mathrm{miR}$. Then, our results suggested that both histone acetylation and miR modulation could act in concert to control MMP-9 expression in a context of glucocorticoid resistance.

In relapsed or refractory multiple myeloma, new therapeutic strategies headed towards treatments using glucocorticoids and/or HDAC inhibitors (28). However, as we demonstrated before, HAT/HDAC balance modifications can cause an upregulation of MMP-9 known to be involved in the bone matrix destruction. Then, we studied the impact of HDACi treatment on MMP-9 expression in glucocorticoid-resistance 
cell lines. Both pan-inhibitor and class I HDACi drastically increased $M M P-9$ mRNA, whereas class II HDACi remained ineffective. The increase of MMP-9 secretion was more pronounced in glucocorticoid-sensitive cells than in glucocorticoid-resistant cells in response to HDACi treatment. However, the MMP-9 mRNA levels reached upon HDACicell stimulation were similar in glucocorticoid-sensitive and -resistant cells, suggesting that differences in MMP-9 secretion must be related to a post-transcriptional regulatory mechanism. This hypothesize was strengthen by ChIP experiments showing a similar $M M P-9$ promoter activity in all cell lines despite the difference of the acetylation status within the $M M P-9$ promoter. Also, mRNA stability experiments argued in favor of a post-transcriptional regulation of $M M P-9$ expression (data not shown). Then, in setting with the potential interplay between histone acetylation regulation and $\mathrm{miR}$ expression modulation raised above, we found that HDACi induced variations in the expression level of different miR directly or indirectly involved in the regulation of MMP-9 expression (44-47). Upon MS-275 treatment, the expression of mature miR-149 was completely abolished, while MMP-9 secretion was increased in all cell types, supporting the relation between the glucocorticoid cell responsiveness, the acetylation status, the miR-149 expression level and the MMP-9 secretion demonstrated above. Of note, in all MS-275 stimulated cell lines, the MMP-9 secretion was much more elevated as compared to the basal secretions observed without MS-275 treatment. However, upon MS-275 treatment, this secretion was lower in glucocorticoid-resistant cells with respect to sensitive-cells contrary to basal secretion, therefore suggesting the activation of another regulatory mechanism. Among several potential miR, we highlighted the differential expression of miR-520c in both glucocorticoid-sensitive and -resistant cells upon MS-275 stimulation. Then, our results are in line with previous studies that showed that miR-520c increased MMP-9 expression and secretion $(45,48,49)$. Indeed, Liu and Wilson (45) showed that miR-520c indirectly upregulates MMP-9 expression by targeting mTOR and therefore Ras/Raf/MEK/Erk pathway in human fibrosarcoma cells.

In conclusion, we demonstrated for the first time that a glucocorticoid long-term exposure induces a complex epigenetic regulation of MMP-9 expression and secretion, which involves interplay between the histone acetylation mechanisms and miR expression. Independently of glucocorticoid resistance, this interplay is also involved in an increase of MMP-9 expression and secretion upon HDACi treatment. Then, our results raise the possibility that histone acetylation and $\mathrm{miR}$ interactions could lead to the establishment of a new powerful mechanism involved in proinflammatory and/or metastasis gene expression. As inhibitors of HDAC activity have clinical application, our results raise the question of the relevance of HDACi in certain clinical settings in which inflammatory and/or metastasis gene expression, especially MMP-9, have a critical role in the associated pathophysiological mechanisms.

\section{Acknowledgements}

Marwa Hentati-Kallel is supported by grants from the Champagne-Ardenne region. We thank Professor J. Dufer and Dr V. Genty (University of Reims-Champagne-Ardenne,
France), for kindly providing RPMI-8226 human multiple myeloma cancer cell line and its glucocorticoid-resistant variant $8226 \mathrm{~d}$ and $8226 \mathrm{~m}$ selected upon long-term treatment with dexamethasone and methylprednisolone, respectively.

\section{References}

1. Fichel F, Barbe C, Joly P, Bedane C, Vabres P, Truchetet F, Aubin F, Michel C, Jegou J, Grange F, et al: Clinical and immunologic factors associated with bullous pemphigoid relapse during the first year of treatment: A multicenter, prospective study. JAMA Dermatol 150: 25-33, 2014.

2. Shah JJ, Stadtmauer EA, Abonour R, Cohen AD, Bensinger WI, Gasparetto C, Kaufman JL, Lentzsch S, Vogl DT, Gomes CL, et al: Carfilzomib, pomalidomide, and dexamethasone for relapsed or refractory myeloma. Blood 126: 2284-2290, 2015.

3. Pufall MA: Glucocorticoids and cancer. Adv Exp Med Biol 872: 315-333, 2015.

4. Milara J, Lluch J, Almudever P, Freire J, Xiaozhong Q and Cortijo J: Roflumilast N-oxide reverses corticosteroid resistance in neutrophils from patients with chronic obstructive pulmonary disease. J Allergy Clin Immunol 134: 314-322, 2014.

5. Schmidt S, Rainer J, Ploner C, Presul E, Riml S and Kofler R: Glucocorticoid-induced apoptosis and glucocorticoid resistance: Molecular mechanisms and clinical relevance. Cell Death Differ 11 (Suppl 1): S45-S55, 2004.

6. Barnes PJ: Mechanisms and resistance in glucocorticoid control of inflammation. J Steroid Biochem Mol Biol 120: 76-85, 2010.

7. Vandooren J, Opdenakker G, Loadman PM and Edwards DR: Proteases in cancer drug delivery. Adv Drug Deliv Rev 97: 144-155, 2016.

8. Poplineau M, Doliwa C, Schnekenburger M, Antonicelli F, Diederich M, Trussardi-Régnier A and Dufer J: Epigenetically induced changes in nuclear textural patterns and gelatinase expression in human fibrosarcoma cells. Cell Prolif 46: 127-136, 2013.

9. Poplineau M, Schnekenburger M, Dufer J, Kosciarz A, Brassart-Pasco S, Antonicelli F, Diederich M and TrussardiRégnier A: The DNA hypomethylating agent, 5-aza-2'-deoxycytidine, enhances tumor cell invasion through a transcription-dependent modulation of MMP-1 expression in human fibrosarcoma cells. Mol Carcinog 54: 24-34, 2015.

10. Nicolaides NC, Galata Z, Kino T, Chrousos GP and Charmandari E: The human glucocorticoid receptor: Molecular basis of biologic function. Steroids 75: 1-12, 2010.

11. Ishiguro H, Kawahara T, Zheng Y, Kashiwagi E, Li Y and Miyamoto H: Differential regulation of bladder cancer growth by various glucocorticoids: Corticosterone and prednisone inhibit cell invasion without promoting cell proliferation or reducing cisplatin cytotoxicity. Cancer Chemother Pharmacol 74: 249-255, 2014.

12. González-Muniesa P, Marrades MP, Martínez JA and Moreno-Aliaga MJ: Differential proinflammatory and oxidative stress response and vulnerability to metabolic syndrome in habitual high-fat young male consumers putatively predisposed by their genetic background. Int J Mol Sci 14: 17238-17255, 2013.

13. Park C-S, Lee YS, Kwon H-S, Lee T, Kim TB, Moon KA, Yoo B, Moon HB and Cho YS: Chlamydophila pneumoniae inhibits corticosteroid-induced suppression of metalloproteinase- 9 and tissue inhibitor metalloproteinase-1 secretion by human peripheral blood mononuclear cells. J Med Microbiol 61: 705-711, 2012.

14. Jung SH, Wang Y, Kim T, Tarr A, Reader B, Powell N and Sheridan JF: Molecular mechanisms of repeated social defeatinduced glucocorticoid resistance: Role of microRNA. Brain Behav Immun 44: 195-206, 2015.

15. Bachmann PS, Piazza RG, Janes ME, Wong NC, Davies C, Mogavero A, Bhadri VA, Szymanska B, Geninson G, Magistroni V, et al: Epigenetic silencing of BIM in glucocorticoid poor-responsive pediatric acute lymphoblastic leukemia, and its reversal by histone deacetylase inhibition. Blood 116: 3013-3022, 2010.

16. Wang W, Li JJ, Foster PS, Hansbro PM and Yang M: Potential therapeutic targets for steroid-resistant asthma. Curr Drug Targets 11: 957-970, 2010

17. Barnes PJ: Corticosteroid resistance in patients with asthma and chronic obstructive pulmonary disease. J Allergy Clin Immunol 131: 636-645, 2013. 
18. Kobayashi Y, Wada H, Rossios C, Takagi D, Charron C, Barnes PJ and Ito K: A novel macrolide/fluoroketolide, solithromycin (CEM-101), reverses corticosteroid insensitivity via phosphoinositide 3-kinase pathway inhibition. Br J Pharmacol 169: 1024-1034, 2013.

19. Ito K, Yamamura S, Essilfie-Quaye S, Cosio B, Ito M, Barnes PJ and Adcock IM: Histone deacetylase 2-mediated deacetylation of the glucocorticoid receptor enables NF-kappaB suppression. J Exp Med 203: 7-13, 2006.

20. Barnes PJ, Adcock IM and Ito K: Histone acetylation and deacetylation: Importance in inflammatory lung diseases. Eur Respir J 25: 552-563, 2005

21. Poplineau M, Dufer J, Antonicelli F and Trussardi-Regnier A: Epigenetic regulation of proMMP-1 expression in the HT1080 human fibrosarcoma cell line. Int J Oncol 38: 1713-1718, 2011.

22. Frank A, David V, Aurelie T-R, Florent G, William H and Philippe B: Regulation of MMPs during melanoma progression: From genetic to epigenetic. Anticancer Agents Med Chem 12: 773-782, 2012

23. Tsapis M, Lieb M, Manzo F, Shankaranarayanan P, Herbrecht R, Lutz $\mathrm{P}$ and Gronemeyer H: HDAC inhibitors induce apoptosis in glucocorticoid-resistant acute lymphatic leukemia cells despite a switch from the extrinsic to the intrinsic death pathway. Int J Biochem Cell Biol 39: 1500-1509, 2007.

24. Barillé S, Akhoundi C, Collette M, Mellerin MP, Rapp MJ, Harousseau JL, Bataille R and Amiot M: Metalloproteinases in multiple myeloma: Production of matrix metalloproteinase- 9 (MMP-9), activation of proMMP-2, and induction of MMP-1 by myeloma cells. Blood 90: 1649-1655, 1997.

25. Kelly T, Børset M, Abe E, Gaddy-Kurten D and Sanderson RD: Matrix metalloproteinases in multiple myeloma. Leuk Lymphoma 37: 273-281, 2000.

26. Urbaniak-Kujda D, Kapelko-Slowik K, Prajs I, Dybko J, Wolowiec D, Biernat M, Slowik M and Kuliczkowski K: Increased expression of metalloproteinase-2 and -9 (MMP-2, MMP-9), tissue inhibitor of metalloproteinase-1 and -2 (TIMP-1, TIMP-2), and EMMPRIN (CD147) in multiple myeloma. Hematology 21: 26-33, 2016.

27. Redic KA, Hough SM and Price EM: Clinical developments in the treatment of relapsed or relapsed and refractory multiple myeloma: Impact of panobinostat, the first-in-class histone deacetylase inhibitor. Onco Targets Ther 9: 2783-2793, 2016.

28. Tandon N, Ramakrishnan V and Kumar SK: Clinical use and applications of histone deacetylase inhibitors in multiple myeloma. Clin Pharmacol 8: 35-44, 2016

29. Cai B, Lyu H, Huang J, Wang S, Lee C-K, Gao C and Liu B Combination of bendamustine and entinostat synergistically inhibits proliferation of multiple myeloma cells via induction of apoptosis and DNA damage response. Cancer Lett 335: 343-350, 2013.

30. Yang A, Ma J, Wu M, Qin W, Zhao B, Shi Y, Jin Y and Xie Y: Aberrant microRNA-182 expression is associated with glucocorticoid resistance in lymphoblastic malignancies. Leuk Lymphoma 53: 2465-2473, 2012.

31. Kotani A, Ha D, Hsieh J, Rao PK, Schotte D, den Boer ML, Armstrong SA and Lodish HF: miR-128b is a potent glucocorticoid sensitizer in MLL-AF4 acute lymphocytic leukemia cells and exerts cooperative effects with miR-221. Blood 114 4169-4178, 2009

32. Li G, Bu J, Zhu Y, Xiao X, Liang Z and Zhang R: Curcumin improves bone microarchitecture in glucocorticoid-induced secondary osteoporosis mice through the activation of microRNA-365 via regulating MMP-9. Int J Clin Exp Pathol 8 : 15684-15695, 2015.

33. Genty V, Dine G and Dufer J: Phenotypical alterations induced by glucocorticoids resistance in RPMI-8226 human myeloma cells. Leuk Res 28: 307-313, 2004.
34. Genty V, El-Khoury V, Liautaud-Roger F, Dine G and Dufer J: Nuclear chromatin patterns in 3 glucocorticoid-resistant RPMI-8226 human myeloma cell sub-lines: Correlations with cell growth and immunological phenotype. Cancer Biol Ther 4: 832-839, 2005.

35. Chomczynski P and Sacchi N: Single-step method of RNA isolation by acid guanidinium thiocyanate-phenol-chloroform extraction. Anal Biochem 162: 156-159, 1987.

36. Schneider CA, Rasband WS and Eliceiri KW: NIH Image to ImageJ: 25 years of image analysis. Nat Methods 9: 671-675, 2012.

37. Debret R, Le Naour RR, Sallenave J-M, Deshorgue A, Hornebeck WG, Guenounou M, Bernard P and Antonicelli FD: Elastin fragments induce IL-1beta upregulation via NF-kappaB pathway in melanoma cells. J Invest Dermatol 126: 1860-1868, 2006.

38. Randall MJ, Haenen GRMM, Bouwman FG, van der Vliet A and Bast A: The tobacco smoke component acrolein induces glucocorticoid resistant gene expression via inhibition of histone deacetylase. Toxicol Lett 240: 43-49, 2016.

39. Adcock IM, Ito K and Barnes PJ: Glucocorticoids: Effects on gene transcription. Proc Am Thorac Soc 1: 247-254, 2004.

40. Ma P, Pan H, Montgomery RL, Olson EN and Schultz RM: Compensatory functions of histone deacetylase 1 (HDAC1) and HDAC2 regulate transcription and apoptosis during mouse oocyte development. Proc Natl Acad Sci USA 109: E481-E489, 2012.

41. Karius T, Schnekenburger M, Dicato M and Diederich M: MicroRNAs in cancer management and their modulation by dietary agents. Biochem Pharmacol 83: 1591-1601, 2012.

42. Trécul A, Morceau F, Gaigneaux A, Schnekenburger M, Dicato M and Diederich M: Valproic acid regulates erythro-megakaryocytic differentiation through the modulation of transcription factors and microRNA regulatory micro-networks. Biochem Pharmacol 92: 299-311, 2014.

43. Lim LP, Lau NC, Garrett-Engele P, Grimson A, Schelter JM, Castle J, Bartel DP, Linsley PS and Johnson JM: Microarray analysis shows that some microRNAs downregulate large numbers of target mRNAs. Nature 433: 769-773, 2005.

44. Palmieri D, Capponi S, Geroldi A, Mura M, Mandich P and Palombo D: TNFa induces the expression of genes associated with endothelial dysfunction through p38MAPK-mediated downregulation of miR-149. Biochem Biophys Res Commun 443: 246-251, 2014

45. Liu P and Wilson MJ: miR-520c and miR-373 upregulate MMP-9 expression by targeting mTOR and SIRT1, and activate the Ras/Raf/MEK/Erk signaling pathway and NF- $\kappa \mathrm{B}$ factor in human fibrosarcoma cells. J Cell Physiol 227: 867-876, 2012.

46. Zhou Y, Li Y, Ye J, Jiang R, Yan H, Yang X, Liu Q and Zhang J: MicroRNA-491 is involved in metastasis of hepatocellular carcinoma by inhibitions of matrix metalloproteinase and epithelial to mesenchymal transition. Liver Int 33: 1271-1280, 2013.

47. Ucar A, Vafaizadeh V, Jarry H, Fiedler J, Klemmt PA, Thum T, Groner B and Chowdhury K: miR-212 and miR-132 are required for epithelial stromal interactions necessary for mouse mammary gland development. Nat Genet 42: 1101-1108, 2010.

48. Huang Q, Gumireddy K, Schrier M, le Sage C, Nagel R, Nair S, Egan DA, Li A, Huang G, Klein-Szanto AJ, et al: The microRNAs $\mathrm{miR}-373$ and $\mathrm{miR}-520 \mathrm{c}$ promote tumour invasion and metastasis. Nat Cell Biol 10: 202-210, 2008.

49. Yang K, Handorean AM and Iczkowski KA: MicroRNAs 373 and $520 \mathrm{c}$ are downregulated in prostate cancer, suppress CD44 translation and enhance invasion of prostate cancer cells in vitro. Int J Clin Exp Pathol 2: 361-369, 2009. 